\title{
Staying true to the mission: adapting telepsychiatry to a new environment
}

\author{
Rebecca A. Kornbluh*
}

Telepsychiatry and Program Improvement, Department of State Hospitals, Sacramento, California, USA

First published online 4 March 2014

A shortage of psychiatrists threatens significantly to worsen treatment for the mentally ill. The nation's psychiatric workforce is in crisis. Currently, $77 \%$ of counties in the United States have a severe psychiatrist shortage, ${ }^{1}$ and, with $50 \%$ of psychiatrists over the age of $55,{ }^{2}$ the situation is likely to worsen. Public mental health systems, which are losing traditional advantages such as generous pensions ${ }^{3}$ and stable employment, ${ }^{4}$ face a growing threat from psychiatrist shortages. Public psychiatric services are already scant in more remote areas, where recruitment threatens to become ever more difficult. Given that state revenues are anticipated to rise only slowly, if at all, in the coming years, state psychiatric systems are unlikely to have adequate funding to compete for psychiatrists.

In this context, telepsychiatry provides a potential opportunity to relieve some of the immediate strains on the system. Though telepsychiatry was first introduced in the $1970 \mathrm{~s}$, its use has grown rapidly in the ensuing decades, as improvements in audio and video transmission, coupled with decreased costs, have made it more viable. A number of studies-conducted among populations of different ages and ethnicities, and with varying diagnoses-have pointed to its flexibility. These studies have examined telepsychiatry's success largely from the standpoints of patient satisfaction, symptom improvement, accessibility of care, and cost. Based on these criteria, results indicate that telepsychiatry has provided a level of care comparable with care as usual. ${ }^{5}$ Telepsychiatry is no longer experimental or untested. Policy makers and professional organizations are writing telepsychiatry into standard practice. Medicare has added billing codes specific to telepsychiatry, and the Joint Commission on Accreditation of Healthcare

*Address for correspondence: Rebecca Kornbluh, MD, MPH, Director of Telepsychiatry and Program Improvement, Department of State Hospitals, 1600 9th Street, Room 101, Sacramento, CA 95814, USA.

(Email: Rebecca.Kornbluh@dsh.ca.gov)
Organizations (JCAHO) has added language to expedite the privileging of telepsychiatry. ${ }^{6}$

Public mental health systems are even now exploring the potential benefits of telepsychiatry, which include the following:

- The ability to recruit psychiatrists from dense population centers to serve remote areas, which are suffering from unmet need

- The possibility of maintaining a psychiatric workforce that can be deployed to multiple areas, depending on demand

- The likelihood of attracting a more competitive applicant pool, thus increasing selectivity

Telepsychiatry has already established itself in a number of areas, most notably in outpatient settings, correctional institutions, and emergency rooms. In these settings, the psychiatrist provides an assessment through a discrete "visit," a model that is already widespread and well established. Many state and federal agencies, for example, are using telepsychiatry successfully in these venues. Additionally, there are many contractors willing to provide telepsychiatry services, as a simple Internet search reveals.

However, as telepsychiatry moves into inpatient, partial hospital, and home healthcare settings, we need more carefully to define the model of care it should be supporting. As tempting as it may be to transpose telepsychiatry directly onto new settings, this could destabilize the current model of care. Public psychiatric hospitals, in particular, pose a serious challenge to the implementation of telepsychiatry, due to the complexity of treatment and discharge. Public psychiatry focuses more on "recovery principles" of care, which aspire to move beyond treating symptoms and managing illness. This has generated a multidisciplinary approach; a static and restricted "visit" model can be less helpful. ${ }^{7}$ In such settings, a multidisciplinary team is often led by an attending psychiatrist, who leads the team, and is legally 
and ethically responsible for the care of patients. Such leadership, at its best, brings a team together to support a patient's recovery, as envisioned in recovery principles. There is a danger that telepsychiatry will disrupt the clinical ecology of state psychiatric hospitals, thereby vitiating their recovery orientation. We must insist that telepsychiatry serve the standing mission of our clinical system, not the other way around.

If telepsychiatry is to serve the existing recovery model of public hospitals, then it must be judged on the basis of how it supports such care. In other words, we need to build in outcome measurements from the very beginning, and the outcomes we choose must focus on the criteria mandated by recovery principles. Clinical and administrative leaders assert the priorities of an institution through the outcome measurements they select. Previous studies about the effectiveness of telepsychiatry have measured only a limited number of outcomes; the focus has been mostly on symptom management, cost, feasibility, and patient satisfaction. ${ }^{5}$ But such measurements are insufficient to demonstrate the viability of telepsychiatry within the broader mission of a recovery-oriented institution. In addition to measuring the severity of symptoms or simple patient satisfaction, recovery-oriented hospitals need to know about other things, such as quality of life, and selfassessments of health and functioning.

Great challenges sometimes provide great opportunities. Telepsychiatry, once imagined as a stopgap measure to solve a crisis of availability, could prove to be much more than that. It could revolutionize the way we access and provide care. But we cannot, swayed by vague promises of path-breaking new technology, lose sight of our fundamental treatment model. In other words, we cannot serve the needs of telepsychiatry; telepsychiatry must serve us and our patients. To ensure that it does, we must both focus and broaden the outcomes we measure. Only in that way can we ensure that telepsychiatry will strengthen and support our mission.

\section{Disclosure}

Rebecca Kornbluh has nothing to disclose.

\section{REFERENCES:}

1. Konrad TR, Ellis AR, Thomas JC, et al. County-level estimates of need for mental health professionals in the United States. Psychiatr Serv. 2009; 60(10): 1307-1314.

2. Vernon DJ, Salsberg E, Erikson C, Kirch DG. Planning the future mental health workforce: with progress on coverage, what role will psychiatrists play? Acad Psychiatry. 2009; 33(3): 187-192.

3. Government Accountability Office. State and local government pension plans: economic downturn spurs efforts to address cost and sustainability. GAO 12-322. March 2012. http://www.gao.gov/ assets/590/589043.pdf. Accessed November 20, 2013.

4. Maynard M. Shedding government jobs? Stateline: the daily news service of the Pew Charitable Trust. February 21, 2013. http:/www.pewstates.org/projects/stateline/headlines/state-andlocal-government-employment-trends-85899452772. Accessed November 15, 2013

5. Hilty DN, Ferrer DC, Parish MB, et al. The effectiveness of telemental health: a 2013 review. Telemed J E Health. 2013; 19(6): 444-454

6. Joint Commission on Accreditation of Healthcare Organizations. Joint Commission perspectives. 2012;32(1): 4-6.

7. Barber ME. Recovery as the new medical model for psychiatry. Psychiatr Serv. 2012; 63(3): 277-279. 